\title{
Türkiye'deki Mevduat Bankalarının Fiyat-Kazanç Oranını Etkileyen Değişkenlerin Mars Yöntemi İle Belirlenmesi
}

\author{
Serhat YÜKSEL ${ }^{1}$, İsmail CANÖZ ${ }^{2}$, Zafer ADALI $^{3}$
}

\section{Determination of the Variables Affecting the Price Earning Ratios of Deposit Banks in} Turkey by Mars Method

\begin{tabular}{l} 
ARTICLE INFO \\
\hline Article History: \\
Date Submitted: 20.06 .2017 \\
Date Accepted: 11.10 .2017 \\
\hline JEL Classification: \\
G12 \\
G17 \\
G21
\end{tabular}

Keywords:

Banking

Price-Earning Ratio MARS

\begin{abstract}
In this study, it is aimed to identify the factors influencing the price-earnings ratio of deposit banks in Turkey. In this context, quarterly cumulative data of 10 deposit banks traded in Istanbul Stock Exchange for the periods between 2002:4 and 2017:1 is analyzed by using MARS method. According to the analysis results, it is concluded that if the ROE of the banks is higher than $5.92 \%$, it affects price-earning ratio positively. However, this effect will be negative when ROE exceeds $21.12 \%$. This indicates that investors are willing to pay more for the stocks of the banks when their profitability is increasing. Besides, it is also identified that there is an adverse relationship between the market interest rate and NPL of the banks with the price-earnings ratio. In case of any raise in the interest rate and NPL of the banks, investors' expectation of the future profitability of the banks will be negative. As a result, it is understood that the investors are reluctant to pay more amounts to their bank shares.
\end{abstract}

\footnotetext{
${ }^{1}$ Yrd. Doç. Dr., İstanbul Medipol Üniversitesi, İşletme ve Yönetim Bilimleri Fakültesi, İngilizce İşletme Bölümü Öğretim Üyesi, serhatyuksel@medipol.edu.tr

${ }^{2}$ Ar. Gör., İstanbul Arel Üniversitesi, Uygulamalı Bilimler Yüksekokulu, Bankacılık ve Finans Bölümü, ismailcanoz@arel.edu.tr

${ }^{3}$ Ar. Gör., Artvin Çoruh Üniversitesi, Hopa İktisadi ve İdari Bilimler Fakültesi, İktisat Bölümü, zaferadali@artvin.edu.tr
} 


\section{Özet}

$\mathrm{Bu}$ çalışmada Türkiye'deki mevduat bankalarının fiyat-kazanç oranını etkileyen faktörler belirlenmeye çalışılmıştır. Bu bağlamda, Borsa İstanbul'da işlem gören 10 adet mevduat bankasına ait 2002:4-2017:1 dönem aralığındaki 3'er aylık toplu veriler MARS yöntemi kullanılarak analiz edilmiştir. Elde edilen analiz sonuçlarına göre, bankaların özsermaye karlılığının \%5.92'nin üzerinde olduğu durumda fiyat-kazanç oranını arttırıcı yönde etki ettiği, fakat ilgili oranın \%21.12'nin üzerine çıktığı durumda ise bu etkinin negatif olduğu görülmüştür. $\mathrm{Bu}$ husus, bankaların özsermaye karlığının \%21.12 seviyesine gelene kadar yatırımcıların ilgili bankaların hisselerine daha fazla tutar ödemekte istekli olduklarını göstermektedir. Bunun yanı sıra, piyasa faiz oranı ve bankalarının takipteki krediler oranı ile fiyat-kazanç oranı arasında negatif yönlü bir ilişki bulunduğu belirlenmiştir. Faiz oranının yükseldiği ve takipteki krediler oranının arttığı durumda yatırımcıların bankaların gelecekteki karlılığına yönelik beklentilerinin olumsuz olduğu görülmüştür. Bunun sonucunda da söz konusu yatırımcıların banka hisselerine daha fazla tutar ödemekte isteksiz oldukları anlaşılmaktadır.

\section{Anahtar Kelimeler: Bankacılık, Fiyat-Kazanç Oranı, MARS}

\section{Giriş}

Bankalar fon fazlası olan yatırımcılar ile fona ihtiyacı olan kurumları bir araya getirmektedirler. Bu sayede, yatırımcılar ellerinde bulunan fonlarından gelir sağlama imkanı elde etmektedirler. Bunun yanı sıra, ülkede fona ihtiyacı olanlar da bankalar sayesinde bu ihtiyaçlarını giderebilmektedirler. Söz konusu açıklamalardan da anlaşılabileceği gibi bankalar ülke ekonomisinin gelişmesi adına önemli bir rol üstlenmektedirler (Ersin ve Duran, 2017). Bu sebeple, bankaların performansının yüksek olması ülkedeki fon akışının sağlıklı bir şekilde sürdürülebilmesi adına gereklidir (Haldane vd., 2016).

Performansın ölçülebilmesi için birçok farklı yöntem bulunmaktadır. Bu bağlamda, şirketin kar rakamı performans ölçümü adına kullanılabilen bir kalemdir. Buna karşın, şirketin kar rakamının tek başına performans ölçüm kriteri olarak belirlenmesine yönelik birçok eleştiri bulunmaktadır. Bu hususun en temel nedeni farklı büyüklüklerdeki iki farklı şirketin aynı kar 
rakamına sahip olmasının eşit performans anlamına gelmemesidir. Bu örnekte, hacmi küçük olan şirket diğerine nazaran daha yüksek bir performans sergilemiştir. Bundan dolayı, performans ölçümünde kar rakamı, "toplam aktifler" veya "toplam özkaynak” gibi kalemlere oranlanarak daha gerçekçi bir performans kriterine ulaşılması amaçlanmaktadır (Christodoulou vd., 2016).

Fiyat kazanç oranı da şirket değerlemelerinde kullanılan diğer bir yöntemdir. Söz konusu oran "Hisse Senedi Fiyatı/Hisse Başına Net Kar” şeklinde hesaplanmaktadır. Öte yandan, formül içerisinde yer alan "Hisse Başına Net Kar" değeri de "Net Kar/Hisse Senedi Sayısı" oranı ile elde edilmektedir (Ramcharran, 2002). Fiyat kazanç oranı sayesinde şirketlerin finansal performanslarını karşılaştırabilmek mümkün olmaktadır. İlgili oranda, şirketin karı bazında hisse senedi fiyatının ne kadar olduğu ifade edilmektedir. Diğer bir ifadeyle, şirketten elde edilecek kar amacıyla yatırımcıların söz konusu şirketin hisse senedine ne kadar ödemek için gönüllü olduğu bilgisine ulaşılmaktadır.

Fiyat kazanç oranının yüksek olduğu durumda, yatırımcıların şirketin hisse senedine önem gösterdiği anlaşılmaktadır. Başka bir deyişle, yatırımcılar şirketin karının gelecekte artacağını tahmin etmektedirler ve bu yüzden de şirketin hisse senetlerine yatırım yapmaktadırlar (Park, 2000). Öte yandan, fiyat kazanç oranının düşük olması ise yatırımcılar tarafından şirketin hisse senetlerine gösterilen önemin azaldığını ifade etmektedir. Böyle bir durumda da yatırımcıların şirketin gelecek karına yönelik beklentilerinin olumsuz yönde olduğu anlaşılmaktadır.

Bu çalışmada, Türkiye'deki bankaların fiyat-kazanç oranına etki eden hususların belirlenmesi amaçlanmaktadır. Bu bağlamda, Borsa İstanbul'da işlem gören 10 adet mevduat bankasına ait 2002:4-2017:1 dönem aralığındaki 3'er aylık toplu verileri inceleme kapsamına alınmıştır. Yapılan analizlerde, hem bu alanda daha önce kullanılmamış bir model olmasından hem de kullanıldığı çalışmalarda oldukça başarılı sonuçlar vermesinden dolayı MARS yöntemi tercih edilmiştir. Elde edilecek analiz sonuçlarına göre, bankaların fiyat-kazanç oranının arttırılabilmesi için gerekli olan önerilerde bulunabilmek mümkün olacaktır. Adı geçen oran bankacılık sektöründe ilk defa analiz edilerek literatüre katkı sağlanabilmesi hedeflenmektedir. 


\section{Literatür Taraması}

Literatürde fiyat-kazanç oranını etkileyen değişkenleri inceleyen sınırlı sayıda çalışma mevcuttur. Söz konusu çalışmaların bazıları tablo 1'de özetlenmiştir.

Tablo 1: Literatür Özeti

\begin{tabular}{|c|c|c|c|}
\hline Yazar & Yöntem & Kapsam & Sonuç \\
\hline $\begin{array}{c}\text { Beaver ve } \\
\text { Morse (1978) }\end{array}$ & $\begin{array}{l}\text { Regresyon } \\
\text { Analizi }\end{array}$ & $\mathrm{ABD}$ & $\begin{array}{l}\text { Risk ve hisse başı kardaki büyüme ile fiyat-kazanç } \\
\text { oranı arasında istatistiksel açıdan anlamlı bir ilişki } \\
\text { bulunamamıştır. }\end{array}$ \\
\hline $\begin{array}{c}\text { Zarowin } \\
(1990)\end{array}$ & $\begin{array}{l}\text { Regresyon } \\
\text { Analizi }\end{array}$ & $\mathrm{ABD}$ & $\begin{array}{l}\text { Hisse baş kardaki büyüme oranı, fiyat-kazanç oranının } \\
\text { başlıca belirleyicisidir. }\end{array}$ \\
\hline Alford (1992) & \begin{tabular}{|c|}
$\begin{array}{c}\text { Betimleyiciİst } \\
\text { atistik }\end{array}$ \\
\end{tabular} & $\mathrm{ABD}$ & $\begin{array}{l}\text { Fiyat-kazanç oranı ile hisse başı kardaki büyüme ve } \\
\text { risk arasında bir ilişki bulunmamaktadır. }\end{array}$ \\
\hline $\begin{array}{l}\text { Kane vd. } \\
(1996)\end{array}$ & $\mathrm{ARCH}$ & $\mathrm{ABD}$ & $\begin{array}{l}\text { Volatilitenin fiyat-kazanç oranı üzerinde negatif bir } \\
\text { etkisi olduğu sonucuna varılmıştır. }\end{array}$ \\
\hline Park (2000) & $\begin{array}{l}\text { Regresyon } \\
\text { Analizi }\end{array}$ & $\mathrm{ABD}$ & $\begin{array}{l}\text { Faiz oranı ve hisse başı kardaki büyüme fiyat-kazanç } \\
\text { oranını açıklayan değişkenlerdir. }\end{array}$ \\
\hline White (2000) & $\begin{array}{l}\text { Regresyon } \\
\text { Analizi }\end{array}$ & $\mathrm{ABD}$ & $\begin{array}{l}\text { Kar payı dağıtım oranı, volatilite, enflasyon, büyüme } \\
\text { oranı ve uzun vadeli tahvil getiri oranı fiyat-kazanç } \\
\text { oranını açıklayan değişkenlerdir. }\end{array}$ \\
\hline $\begin{array}{l}\text { Ramcharran } \\
\text { (2002) }\end{array}$ & $\begin{array}{l}\text { Regresyon } \\
\text { Analizi }\end{array}$ & $\begin{array}{l}\text { Gelişmekte } \\
\text { Olan } 21 \\
\text { Piyasa } \\
\end{array}$ & $\begin{array}{l}\text { Ekonomik büyümenin fiyat-kazanç oranını etkilediği } \\
\text { sonucuna ulaş1lmıştır. }\end{array}$ \\
\hline $\begin{array}{l}\text { Shamsuddin } \\
\text { ve Hillier } \\
\text { (2004) }\end{array}$ & $\begin{array}{l}\text { Regresyon } \\
\text { Analizi }\end{array}$ & Avustralya & $\begin{array}{l}\text { Kar payı dağıtım oranı, ekonomik büyüme, döviz kuru, } \\
\text { faiz oranı ve volatilite ile fiyat-kazanç oranı arasında } \\
\text { anlamlı bir ilişki bulunmaktadır. }\end{array}$ \\
\hline Öztürk (2007) & $\begin{array}{l}\text { Regresyon } \\
\text { Analizi }\end{array}$ & Türkiye & $\begin{array}{l}\text { Kar payı dağıtım oranı, hisse başı kardaki büyüme } \\
\text { oran1, risk ve firma büyüklüğü fiyat-kazanç oran1 } \\
\text { etkilemektedir. }\end{array}$ \\
\hline $\begin{array}{l}\text { Mahmood vd. } \\
\text { (2007) }\end{array}$ & $\begin{array}{l}\text { Granger } \\
\text { Nedensellik } \\
\text { Analizi }\end{array}$ & Malezya & $\begin{array}{l}\text { Fiyat kazanç oranının hisse getirilerinin önemli bir } \\
\text { nedeni olduğu belirlenmiştir. }\end{array}$ \\
\hline Khan (2009) & $\begin{array}{c}\text { Regresyon } \\
\text { Analizi }\end{array}$ & Pakistan & $\begin{array}{l}\text { Fiyat kazanç oranı ile defter değeri arasında ilişki } \\
\text { bulunmamaktadır. }\end{array}$ \\
\hline Sezgin (2010) & $\begin{array}{l}\text { Granger } \\
\text { Nedensellik } \\
\text { Analizi }\end{array}$ & Türkiye & $\begin{array}{l}\text { Hisse senedi getirisi fiyat-kazanç oranını negatif; kar } \\
\text { payı getirisi ise pozitif etkilemektedir. }\end{array}$ \\
\hline $\begin{array}{l}\text { Nargelecekenl } \\
\text { er (2011) }\end{array}$ & $\begin{array}{l}\text { Regresyon } \\
\text { Analizi }\end{array}$ & Türkiye & $\begin{array}{l}\text { Fiyat kanaç oranının hisse senedi fiyatlarını } \\
\text { etkilemediği anlaşılmaktadır. }\end{array}$ \\
\hline $\begin{array}{c}\text { Afza ve Tahir } \\
(2012)\end{array}$ & $\begin{array}{l}\text { Regresyon } \\
\text { Analizi } \\
\end{array}$ & Pakistan & $\begin{array}{l}\text { Kar payı dağıtım oranı ile fiyat-kazanç oranı arasında } \\
\text { anlamlı bir ilişki bulunmaktadır. }\end{array}$ \\
\hline $\begin{array}{l}\text { Lutfi ve } \\
\text { Arsitha } \\
(2016)\end{array}$ & $\begin{array}{l}\text { Varyans } \\
\text { Analizi }\end{array}$ & Endonezya & $\begin{array}{l}\text { Toplam varlıklar ve borç-özkaynak oranı fiyat-kazanç } \\
\text { oranını anlamlı şekilde etkilemektedir. }\end{array}$ \\
\hline
\end{tabular}


Tablo 1'den görülebileceği gibi çalışmaların bir bölümünde fiyat-kazanç oranını nelerin etkilediği belirlenmeye çalışılmıştır. Zarowin (1990) çalışmasında 1964-1968 yılları arasındaki veriler regresyon yöntemiyle analiz etmiştir. Uzun dönem hisse başı kardaki büyüme oranının, fiyat-kazanç oranını açıklayan başlıca değişken olduğu sonucuna ulaşmıştır. Ayrıca riskin (beta ${ }^{4}$ ) ve kısa dönem hisse başı kardaki büyümenin fiyat-kazanç oranını açıklamada önemli belirleyiciler olmadığını saptamıştır. Buna benzer olarak Beaver ve Morse (1978) ve Alford (1992) çalışmalarında fiyat-kazanç rasyosu ile hisse getirilerindeki büyüme ve risk arasında istatistiksel olarak anlamlı bir ilişki olmadığı sonucuna varmıştır.

Belirtilen çalışmalara ek olarak, White (2000) çalışmasında S\&P 500 indeksinden alınan 1926-1997 dönem aralığındaki 3'er aylık verileri analiz ederek fiyat-kazanç oranını açıklayan değişkenlerin neler olduğunu belirlemeye çalışmıştır. Kar payı dağıtım oranı, kar payı getirisi, hisse başı kardaki büyüme, volatilite, enflasyon, GSYH'deki büyüme oranı ve uzun vadeli tahvil getiri oranının fiyat-kazanç oranını açıklayan değişkenler olduğu sonucuna varmıştır. Benzer şekilde Kane vd. (1996) çalışmalarında fiyat-kazanç oranı ve volatilite arasında istatistiksel olarak anlamlı bir ilişkinin olduğunu ve artan volatilitenin fiyat-kazanç oranını düşürdüğünü saptamışlardır. Ramcharran (2002) ise çalışmasında GSYH'deki büyümenin fiyat-kazanç oranını anlamlı şekilde etkilediği sonucuna ulaşmıştır. Park (2000) çalışmasında hisse başı kardaki büyüme ve faiz oranının fiyat-kazanç oranını açıklayan değişkenler olduğunu tespit etmiştir.

Öte yandan, Shamsuddin ve Hillier (2004) çalışmalarında 1984:01-2001:3 dönem aralığındaki 3'er aylık verileri kullanarak fiyat-kazanç oranını etkileyen değişkenlerin neler olduğunu belirlemeye çalışmışlardır. Buna göre kar payı dağıtım oranındaki artış, GSYH'deki büyüme ve yerel para biriminin değer kazanması fiyat-kazanç oranını artırırken, volatilite ve faiz oranlarındaki artış fiyat-kazanç oranını düşürdüğü sonucuna varmışlardır. Ayrıca, Afza ve Tahir (2012) çalışmalarında 2005-2009 yılları arasında Karachi Borsası'nda işlem gören ve kimya endüstrisinde faaliyet gösteren 25 firmaya ait verileri regresyon analiziyle incelemiştirler. Analiz sonucuna göre, özellikle kar payı dağıtım oranı ve Tobin'nin Q'su değişkenlerinin fiyat-kazanç oranı üzerinde istatistiki olarak anlamlı bir etkisi vardır. Lutfi ve

\footnotetext{
${ }^{4}$ Beta: Sermaye varlığı fiyatlandırma modelinde riski istatistik olarak ölçmek için kullanılır.
} 
Arsitha (2016) çalışmalarında şirketlere ait mikroekonomik göstergelerin şirketlerin fiyatkazanç oranına etkisi olup olmadığını incelemişlerdir. Toplam varlıklar ve Borç/Özkaynak oranı fiyat-kazanç oranını etkilerken, kar payı dağıtım oranı etkilememektedir.

Türkiye'deki çalışmalar incelendiğinde Öztürk (2007) 2002-2006 döneminde İMKB'de işlem gören ve bu dönem içinde kar dağıtan firmaların tamamına ait verileri bütünleşik regresyon analiziyle incelemiştir. Araştırma sonucunda, kar payı dağıtım oranı, hisse başı kardaki büyüme oranı ve risk ile fiyat-kazanç oranı arasında pozitif, firma büyüklüğü ile negatif bir ilişki olduğu tespit edilmiştir. Sezgin (2010) ise fiyat-kazanç oranı ile hisse senedi getirisi ve kar payı getirisi arasındaki ilişkiyi Granger Nedensellik Analizi ile incelemiştir. Analiz sonucunda hisse senedi getirisinin uzun dönemde fiyat-kazanç oranını negatif, kar payı getirisinin hem uzun hem kısa dönemde fiyat-kazanç oranını pozitif etkilediğini tespit etmiştir. Ayrıca nedenselliğin yönü hisse senedi ve kar payı getirisinden fiyat-kazanç oranına doğrudur.

Tablo 1'deki çalışmalar dikkate alındığında, fiyat-kazanç oranını etkileyen çalışmaların sayısının az olduğu anlaşılmaktadır. Öte yandan var olan çalışmaların hiçbirinde de bankacılık sektörünün analiz edilmediği görülmektedir. Bunlara ek olarak, Türkiye'deki fiyat kazanç oranını inceleyen bir çalışmanın en son 2010 yılında yapıldığı belirlenmiştir. Bundan dolayı, Türkiye'deki bankacılık sektörünün fiyat-kazanç oranını inceleyen yeni bir çalışmanın literatüre katkıda bulunacağı düşünülmektedir.

\section{Türk Bankacılık Sektörü Üzerine Bir Uygulama}

\subsection{Veri Seti ve Değişkenler}

Çalışmada Borsa İstanbul'da faaliyet gösteren 10 adet mevduat bankasının 2002:42017:1 dönem aralığındaki 3'er aylık toplu verileri inceleme kapsamına alınmıştır. Söz konusu veriler, Borsa İstanbul, Türkiye Cumhuriyet Merkez Bankası ve Türkiye Bankalar Birliği'ne ait internet sitelerinden temin edilmiştir. Çalışmada inceleme kapsamına alınan 10 mevduat bankasının isimlerine aşağıda yer verilmiştir.

- Akbank

- Denizbank

- Finansbank 
- ICBC Türkiye

- Şekerbank

- Türkiye Garanti Bankası

- Türkiye Halk Bankası

- Türkiye İş Bankası

- Türkiye Vakıflar Bankası

- Yapı ve Kredi Bankası

Literatürde yer alan benzer çalışmaların incelenmesi neticesinde, fiyat-kazanç oranına etki edebileceği düşünülen 8 farklı değişken belirlenmiştir. Söz konusu değişkenlerin detaylarına tablo 2'de yer verilmiştir.

Tablo 2: Çalışmada Kullanılan Değişkenler

\begin{tabular}{|c|c|c|c|}
\hline $\begin{array}{l}\text { Değişken } \\
\text { Türü }\end{array}$ & $\begin{array}{l}\text { Değişken } \\
\text { Adı }\end{array}$ & $\begin{array}{l}\text { Değişken } \\
\text { Açıklaması }\end{array}$ & Referans \\
\hline \multirow{5}{*}{ İçsel } & Karlilik & Net Kar/Özkaynak & $\begin{array}{l}\text { Zarowin (1990), Park (2000), White (2000), } \\
\text { Öztürk (2007), Sezgin (2010), Beaver ve } \\
\text { Morse (1978), Alford (1992) }\end{array}$ \\
\hline & Piyasa Riski & $\begin{array}{l}\text { YP Aktifler / YP } \\
\text { Pasifler }\end{array}$ & $\begin{array}{l}\text { Öztürk (2007), Beaver ve Morse (1978), } \\
\text { Zarowin (1990), Alford (1992) }\end{array}$ \\
\hline & Kredi riski & $\begin{array}{l}\text { Takipteki Krediler } \\
\text { (brüt) / Toplam } \\
\text { Krediler }\end{array}$ & Ramcharran (2002) \\
\hline & $\begin{array}{c}\text { Toplam } \\
\text { Varliklar }\end{array}$ & $\begin{array}{l}\text { Toplam aktiflerin } \\
\text { sektör pay1 }\end{array}$ & $\begin{array}{l}\text { Anderson ve Brooks (2005), Öztürk (2007), } \\
\text { Lutfi ve Arsitha (2016), Afza ve Tahir (2012) }\end{array}$ \\
\hline & Borçluluk & $\begin{array}{l}\text { Toplam Borç/Öz } \\
\text { kaynaklar }\end{array}$ & $\begin{array}{l}\text { Lutfi ve Arsitha (2016), Shamsuddin ve Hillier } \\
\text { (2004) }\end{array}$ \\
\hline \multirow{3}{*}{ Dişsal } & Faiz Oranı & $\begin{array}{l}3 \text { aylik mevduat } \\
\text { faiz oranlanı }\end{array}$ & Park (2000), Shamsuddin ve Hillier (2004) \\
\hline & Enflasyon & $\begin{array}{l}\text { Y1ll1k enflasyon } \\
\text { oranı }\end{array}$ & White (2000) \\
\hline & $\begin{array}{l}\text { Ekonomik } \\
\text { büyüme }\end{array}$ & $\begin{array}{l}\text { Gayrı Safi Milli } \\
\text { Hasıla'nın y1llık } \\
\text { büyüme oranı }\end{array}$ & $\begin{array}{l}\text { White (2000), Ramcharran } \\
\text { Shamsuddin ve Hillier (2004) }\end{array}$ \\
\hline
\end{tabular}

Tablo 2'den de görülebileceği üzere 8 adet bağımsız değişkenin 5 adedi bankalara özgü, 5 adedi ise makroekonomik değişkenlerdir. Karlılık fiyat-kazanç oranını pozitif yönde etkileyebilecek olan önemli bir değişkendir (Alford, 1992). Buna paralel olarak, toplam varlıkları yüksek olan bankanın da fiyat-oranının yüksek olması beklenmektedir (Afza ve Tahir, 2012). Buna karşın, piyasa riski, kredi riski ve borçluluk durumu gibi içsel değişsken ile fiyat- 
kazanç oranı arasında ters yönlü bir ilişki bulunması öngörülmektedir (Zarowin, 1990), (Ramcharran, 2002).

İçsel değişkenlerin yanı sıra, 3 adet dışsal değişken de dikkate alınmıştır. Faiz oranı ile fiyat-kazanç oranı arasında ters yönlü bir ilişki bulunması beklenmektedir. Bunun en temel nedeni bankaların mevduatlarının vadesi kısa iken kredilerinin vadesinin ise uzun olmasıdır. Belirtilen bu vade uyumsuzluğundan dolayı, faiz oranının artması bankaları olumsuz yönde etkilemektedir (Shamsuddin ve Hillier, 2004). Bunun yanı sıra, belirsizliği arttırdığından dolayı enflasyon oranı ile fiyat-kazanç oranı arasında negatif yönlü bir ilişki bulunması beklenmektedir (White, 2000). Öte yandan, ülkedeki ekonomik performansın en önemli göstergesi olan ekonomik büyümenin artması ise fiyat-kazanç oranını olumlu bir şekilde etkileyecektir (Ramcharran, 2002), (Shamsuddin ve Hillier, 2004).

\subsection{MARS Yöntemi}

MARS yöntemi fizikçi Jerome Friedman tarafından değişkenler arasındaki ilişkiyi analiz edebilmek için geliştirilmiş olan bir yöntemdir. Türkçe'de "Çok Değişkenli Uyumlu Regresyon Uzanımları” şeklinde adlandırılmaktadır. Modelin oluşturulma sürecinde ilk olarak, bağımsız değişkenlerin farklı kombinasyonlarını kullanarak bağımlı değişkene etki eden temel fonksiyonlar oluşturulmaktadır. Bu temel fonksiyonlar ile farklı modeller elde edilmektedir. Modelin oluşturulmasının ikinci sürecinde ise elde edilmiş olan en karmaşık model içerisinden MARS sistemi tarafindan bazı anlamsız olan temel fonksiyonlar elenmekte ve en iyi modele ulaşılmaktadır (Friedman, 1991). Adı geçen yöntemin detaylarına aşağıda yer verilmiştir.

$$
Y=B_{0}+\sum_{n=1}^{K} a_{n} B_{n}\left(X_{t}\right)+\varepsilon
$$

İlgili eşitlikte "Y" bağımlı değişkeni ifade ederken, " $X$ " bağımsız değişkeni göstermektedir. Öte yandan, " $B_{0}$ " modelin sabit terimini belirtmektedir. Ayrıca, $a_{n}$ ise n. temel fonksiyonun katsayı değerini ifade etmektedir. Analiz sonuçlarında elde edilen $\mathrm{R}^{2}$ değeri modelin açıklama gücünü, GCV değeri ise modelin hata katsayısını vermektedir. Dolayısıyla, en iyi modelin en yüksek $\mathrm{R}^{2}$ ve en düşük GCV değerlerine sahip olmassı beklenmektedir (Dinçer vd., 2017). Yapılan analizlerde kullanılan ekonometrik yöntemlerin çalışmanın amacına ulaşılmasında oldukça önemli bir rol oynamaktadır (Eti ve İnel, 2016). Bundan dolayı, 
çalışmanın analizinde daha önceki uygulamalarda başarılı sonuç veren MARS yönteminin kullanılması ile daha etkin sonuçlara ulaşılacağı düşünülmektedir.

\subsection{Analiz Sonuçları}

Çalışmada ilk olarak 8 adet bağımsız değişkenin birim kök testi yapılmıştır ${ }^{5}$. Bu bağlamda, genişletilmiş Augmented Dickey Fuller birim kök testinden faydalanılmıştır. Bahsi geçen testin sonuçlarına tablo 3 'de yer verilmiştir.

Tablo 3: Birim Kök Testi Sonuçları

\begin{tabular}{|c|c|c|}
\hline \multirow{2}{*}{ Değişken } & \multicolumn{2}{|c|}{ Augmented Dickey Fuller (ADF) Testi } \\
\cline { 2 - 3 } & Düzey Değer (Olasılık) & Birinci Sura Fark Değeri (Olasılık) \\
\hline Karlılık & 0.0027 & - \\
\hline Piyasa Riski & 0.0036 & - \\
\hline Kredi riski & 0.0017 & - \\
\hline Toplam Varlıklar & 0.8585 & 0.0000 \\
\hline Borçluluk & 0.0862 & 0.0000 \\
\hline Faiz Oranı & 0.0492 & - \\
\hline Enflasyon & 0.0000 & - \\
\hline Ekonomik büyüme & 0.0000 & - \\
\hline
\end{tabular}

Tablo 3'den anlaş1labileceği gibi 8 adet değişken içerisinden 6 adedinin düzey değerlerinde durağan oldukları belirlenmiştir. Buna ek olarak, 2 adet değişken ise birinci sıra farkları alınarak durağan hale getirilmiştir. Birim kök testinin akabinde MARS yöntemi kullanılarak fiyat-kazanç oranını etkileyen hususlar belirlenmeye çalışılmıştır. Tablo 4'de MARS yöntemi tarafindan oluşturulan tüm modeller detaylandırılmıştır.

Tablo 4: Elde Edilen Tüm Modeller

\begin{tabular}{|c|c|c|c|}
\hline Temel Fonksiyon Sayısı & Toplam Değişken Sayısı & GCV & GCV R $^{\mathbf{2}}$ \\
\hline 6 & 3 & 0.094 & 0.088 \\
\hline 5 & 3 & 0.083 & 0.194 \\
\hline 4 & 3 & 0.071 & 0.308 \\
\hline $3^{* *}$ & $\mathbf{3}$ & $\mathbf{0 . 0 6 6}$ & $\mathbf{0 . 3 6 3}$ \\
\hline 2 & 3 & 0.080 & 0.218 \\
\hline 1 & 1 & 0.070 & 0.315 \\
\hline
\end{tabular}

${ }^{5}$ MARS yöntemi uygulamasında değişkenlerin farklarının alınması gerekmemektedir. Söz konusu uygulama yazarların kendi tercihleridir. 
Tablo 4'den görülebileceği gibi MARS yöntemi tarafından 6 farklı model oluşturulmuştur. Bu modeller içerisinde temel fonksiyon ve toplam değişken sayısı 3'e eşit olan modelin en iyi model olduğu anlaşılmaktadır. Ayrıca, söz konusu modelin en düşük GCV ve en büyük $\mathrm{R}^{2}$ değerlerine sahip olduğu görülmektedir. Tablo 5'de ise en iyi modelin detayları gösterilmektedir.

\section{Tablo 5: En İyi Modelin Detayları}

\begin{tabular}{|c|c|c|}
\hline Değişken & Katsayı & p Değeri \\
\hline Sabit Terim & 5.518 & 0.00 \\
\hline Temel Fonksiyon 6 & -0.022 & 0.00 \\
\hline Temel Fonksiyon 9 & -0.134 & 0.00 \\
\hline Temel Fonksiyon 14 & 0.008 & 0.00 \\
\hline \multicolumn{2}{|l|}{} & \\
\hline \multicolumn{2}{|l|}{ F Testi: 24.64 [0.000] Düz R²: 0.554 } \\
\hline
\end{tabular}

Tablo 5'den anlaşılabileceği gibi tüm temel fonksiyonların p değerleri 0.01 rakamının altındadır. Bu durum da ilgili fonksiyonların istatistiki olarak anlamlı olduğunu göstermektedir. Ayrıca, F testi de modelin bir bütün olarak anlamlı olduğu bilgisini vermektedir. Tablo 6'da en iyi modelde yer alan temel fonksiyonların detayları verilmektedir.

Tablo 6: Temel Fonksiyonların Detayları

\begin{tabular}{|c|c|c|}
\hline Temel Fonksiyon & Açıklama & Katsayı \\
\hline Temel Fonksiyon 4 & $\max (0$, Karlilik -21.12$)$ & - \\
\hline Temel Fonksiyon 6 & $\begin{array}{l}\max (0, \text { Takipteki Krediler Oranı }-2.82) * \text { Temel } \\
\text { Fonksiyon } 4\end{array}$ & -0.022 \\
\hline Temel Fonksiyon 9 & $\max (0$, Faiz Oran1 - 16.18) & -0.134 \\
\hline Temel Fonksiyon 14 & $\max (0$, Karlilık -5.92$) *$ Temel Fonksiyon 9 & 0.008 \\
\hline
\end{tabular}

Tablo 6'dan anlaşılabileceği üzere 3 adet bağımsız değişken fiyat-kazanç oranını açıklamada anlamlı bulunmuştur. Karlılık değişkeni hem temel fonksiyon 4 hem de temel fonksiyon 14 içerisinde yer almaktadır. Belirtilen hususun yanı sıra, temel fonksiyon 4'ün ayrıca temel fonksiyon 6 içerisinde de yer aldığı görülmektedir. Ayrıca, temel fonksiyon 14'ün katsayısı pozitif (0.008) iken temel fonksiyon 6'nın katsayısı negatif (-0.022) olarak belirlenmiştir. İlgili konular dikkate alındığında, bankaların özsermaye karlılığının \%5.92'nin üzerinde olduğu durumda fiyat-kazanç oranını arttırıcı yönde etki ettiği görülmektedir. 
Öte yandan, söz konusu oranın \%21.12'nin üzerine çıktığı durumda ise karlılığın fiyatkazanç oranı üzerindeki etkisinin negatif olacağı anlaşılmaktadır. İlgili veriler dikkate alındığında, bankaların karlılıklarının arttığı durumda yatırımcıların kar beklentilerinin de arttığı ve bunun sonucunda da banka hisseleri için daha fazla tutar ödemekte istekli oldukları anlaşılmaktadır. Buna karşın, karlılık oranının belirli bir seviyenin üzerine çıkması durumunda ise yatırımcıların bankaların gelecekteki karlılığına yönelik beklentisinin olumsuz olduğu görülmektedir. Bahsi geçen bu sonuç literatürdeki birçok çalışmanın sonuçlarına paraleldir (Sezgin, 2010), (Beaver ve Morse, 1978), (Alford, 1992).

Analiz sonuçlarına göre bankaların fiyat-kazanç oranını etkileyen bir diğer değişken de takipteki krediler oranıdır. Söz konusu değişken temel fonksiyon 6 içerisinde yer almaktadır ve katsayısı -0.022'dir. Belirtilen hususlar dikkate alındığında, Türk bankalarının takipteki krediler oranı ile fiyat-kazanç oranı arasında negatif yönlü bir ilişki bulunduğu belirlenmiştir. Diğer bir ifadeyle, bankaların takipteki kredilerinin toplam kredilerine oranı \%2.82'yi geçtiği durumda fiyat kazanç oranı azalmaktadır. Bunun en temel nedeni bankaların takipteki krediler oranı yüksek olduğu durumda yatırımcıların bankanın gelecekteki karlılığı ile ilgili beklentisinin azalması ve bu yüzden de banka hisselerine yatırım yapmak için isteksiz davranmalarıdır. Ramcharran (2002) da çalışmasında benzer sonuçlara ulaşmıştır.

Son olarak, faiz oranlarındaki değişimin bankaların fiyat-kazanç oranını etkilediği görülmüştür. Adı geçen değişken temel fonksyion 9 içerisinde "max (0, Faiz Oranı - 16.18)" koşulu ile yer almakta olup katsayısı -0.134'dür. Bu husus dikkate alındığında, piyasa faiz oranı \%16.18 seviyesine gelene kadar bankaların fiyat-kazanç oranına etki etmemektedir. Buna karşın, ilgili oranın belirtilen bu seviyeyi aşması durumunda, bu durum fiyat-kazanç oranını olumsuz bir şekilde etkileyecektir. Bu sonucun en temel gerekçesi bankaların topladıkları mevduatların vadelerinin, tahsis ettikleri kredilerin vadelerine göre kısa olmalarıdır. Bundan dolayı, olası bir faiz oranı artışında bu durum bankaları olumsuz yönde etkileyecektir. Bunun sonucunda da yatırımcıların bankaların gelecekteki karlarına yönelik beklentileri azalacaktır.

\section{Sonuç}


Bankaların ülke ekonomisi içinde çok kilit bir rolü olduğu için performanslarının yüksek olması ülkedeki her kesim için çok önemlidir. Bu husustan dolayı bankaların performans ölçümüne yönelik farklı kriterler ele alınmaktadır. "Hisse Senedi Fiyatı/Hisse Başına Net Kar" şeklinde hesaplanan fiyat-kazanç oranı da bankaların performansına yönelik kullanılabilecek olan bir kriterdir. Bu oran, bankadan elde edilecek kar için yatırımcıların söz konusu bankanın hisse senedine ne kadar ödemek için gönüllü olduğu bilgisini vermektedir.

$\mathrm{Bu}$ çalışmada Türkiye' deki mevduat bankalarının fiyat-kazanç oranını etkileyen hususlar belirlenmeye çalışılmıştır. Bu amaçla, Borsa İstanbul'da işlem gören 10 adet mevduat bankası inceleme kapsamına alınmıştır. Ayrıca, literatürdeki benzer çalışmaların incelenmesi neticesinde fiyat-kazanç oranına etki edebileceği düşünülen 8 farklı değişkene ait 2002:42017:1 dönem aralığındaki 3'er aylık toplu veriler inceleme kapsamına alınmıştır. Öte yandan, analiz sürecinde bu alanda ilk defa kullanılacak olan MARS yönteminden faydalanılmıştır.

Analiz sürecinde ilk olarak bağımsız değişkenlerin durağan olup olmadıkları incelenmiştir. Bu bağlamda, genişletilmiş Augmented Dickey Fuller (ADF) birim kök testinden faydalanılmıştır. Analiz sonuçlarına göre, 8 adet değişken içerisinden 6 adedinin düzey değerlerinde durağan oldukları belirlenmiştir. Bunun yanı sıra, 2 adet değişken ise birinci sıra farkları alınarak durağan hale getirilmiştir. Analizde de tüm değişkenlerin durağan halleri kullanılmıştır.

Birim kök testinin akabinde MARS yöntemi kullanılarak Türk mevduat bankalarının fiyat-kazanç oranına etki eden hususlar belirlenmeye çalışılmıştır. MARS yöntemi tarafından 6 farklı model oluşturulmuş ve temel fonksiyon ve toplam değişken sayısı 3'e eşit olan model en iyi model olarak tarfımıza sunulmuştur. En iyi modelde yer alan tüm temel fonksiyonların $p$ değerleri ve modelin F değerine ilişkin anlamlılık seviyesinin 0.01 değerinin altında olduğu belirlenmiştir. Bu durum hem temel fonksiyonların hem de modelin bir bütün olarak anlamlı olduğunu göstermektedir.

Elde edilen analiz sonuçlarına göre, 3 adet bağımsız değişkenin fiyat-kazanç oranını etkilediği tespit edilmiştir. Bankaların özsermaye karlılığının \%5.92’nin üzerinde olduğu durumda fiyat-kazanç oranını arttırıcı yönde etki ettiği, fakat söz konusu oranın \%21.12'nin 
üzerine çıktığı durumda ise karlılığın fiyat-kazanç oranı üzerindeki etkisinin negatif olduğu görülmüştür. $\mathrm{Bu}$ durum, bankaların karlılıklarının arttığı durumda yatırımcıların kar beklentilerinin de arttığı fakat bu seviyenin \%21.12'nin üzerine çıktığı durumda ise yatırımcıların bankaların gelecekteki karlılığına yönelik beklentisinin olumsuz olduğu görülmektedir.

Ayrıca, Türk bankalarının takipteki krediler oranı ile fiyat-kazanç oranı arasında negatif yönlü bir ilişki bulunduğu belirlenmiştir. Takipteki krediler oranı yüksek olduğu durumda yatırımcıların bankaların gelecekteki karlılığına yönelik beklentisinin olumsuz olduğu ve bunun sonucunda da söz konusu yatırımcıların banka hisselerine daha fazla tutar ödemekte isteksiz oldukları anlaşılmaktadır. Bunun dışında, faiz oranlarındaki değişimin bankaların fiyat-kazanç oranını etkilediği görülmüştür. Piyasa faiz oranı \%16.18 seviyesine gelene kadar bankaların fiyat-kazanç oranına etki etmediği, fakat söz konusu oranın belirtilen bu seviyeyi aşması durumunda ise bu etkinin negatif yönde olduğu belirlenmiştir. Topladıkları mevduatların vadesi kullandırdıkları kredilerin vadesine kıyasla kısa olan bankalar faiz oranı artışından olumsuz bir şekilde etkilenecektir. Bunun sonucunda da yatırımcıların bankaların hisse senetlerine yönelik talepleri azalacaktır.

Belirtilen bu sonuçlar dikkate alındığında, fiyat-kazanç oranının artması için bankaların karlılıklarını yükseltmeleri ve müşterilerine kullandırdıkları kredilerde de daha seçici davranmaları gerekmektedir. Fiyat-kazanç oranı Türk bankacılık sektörü için ilk defa bu çalışmada analiz edilerek literatüre katkı sağlanması hedeflenmiştir. Öte yandan, belirtilen bu konunun birçok farklı ülkede ele alınacağı yeni bir çalışmanın da oldukça faydalı olacağı düşünülmektedir. 


\section{Kaynakça}

Anderson, K., \& Brooks, C. (2005). Decomposing The Price-Earnings Ratio. Journal Of Asset Management, 6(6), 456-469.

Afza, T., \& Tahir, S. (2012). Determinants Of Price-Earnings Ratio: The Case Of Chemical Sector Of Pakistan. International Journal of Academic Research in Business and Social Sciences, 2(8), 331.

Alford, A. W. (1992). The Effect Of The Set Of Comparable Firms On The Accuracy Of The Price-Earnings Valuation Method. Journal of Accounting Research, 94-108.

Beaver, W., \& Morse, D. (1978). What Determines Price-Earnings Ratios?. Financial Analysts Journal, 65-76.

Christodoulou, D., Clubb, C., \& Mcleay, S. (2016). A structural accounting framework for estimating the expected rate of return on equity. Abacus, 52(1), 176-210

Dinçer, H., Hacıoğlu, Ü., \& Yüksel, S. (2017). Determining Influencing Factors of Currency Exchange Rate for Decision Making in Global Economy Using MARS Method. Geopolitics and Strategic Management in the Global Economy, 261-273.

Ersin, İ. \& Duran, S. (2017). Faizsiz Finans Döngüsünü Oluşturma Açısından Adil Ekonomik Düzen Söyleminin Kredileşme İlkeleri Ve Uygulanabilirliğinin Değerlendirilmesi. Turkish Studies, 12(8), 109-132.

Eti S. \& İnel, M.N. (2016). A Research on Comparison of Regression Models Explaining the Profitability Base on Financial Data. International Journal of Business and Management, 4(10), 470-475.

Friedman, J. (1991). Multivariate Adaptive Regression Splines. The Annals of Statistics, 19, 1141. 
Haldane, A. G., Millard, S., \& Saporta, V. (2016). The Future of Payment Systems (Routledge International Studies in Money and Banking).

Kane, A., Marcus, A. J., \& Noh, J. (1996). The P/E Multiple And Market Volatility. Financial Analysts Journal, 16-24.

Khan, M. I. (2009). Price Earning Ratio and Market to Book Ratio. IUB Journal of Social Sciences and Humanities, 2(9), 103-112.

Lutfi, M., \& Arsitha, J. (2016). The Analysis of Factors Affecting Price Earnings Ratio on the Company Shares Registered in Jakarta Islamic Index. Academic Journal of Economic Studies, 2(3), 55-63.

Mahmood, W., Mansor, W., Fatah, A., \& Syuhada, F. (2007). Multivariate Causal Estimates of Dividend Yields, Price Earning Ratio and Expected Stock Returns: Experience from Malaysia. MPRA Paper, 14614.

Nargelecekenler, M. (2011). Hisse Senedi Fiyatlari ve Fiyat/Kazanç Orani Iliskisi: Panel Verilerle Sektörel Bir Analiz*/Stock Prices and Price/Earning Ratio Relationship: A Sectoral Analysis with Panel Data. Business and Economics Research Journal, 2(2), 165-184.

Öztürk, M. B. (2007). Fiyat/Kazanç Oranını Etkileyen Değişkenler Üzerine İMKB'de Ampirik Bir Uygulama. Sosyal Bilimler Enstitüsü Dergisi Sayl:23 Yıl:2007/2, 275-284.

Park, S. (2000). What Does The PE Ratio Mean?. The Journal Of Investing, 9(3), 27-34.

Ramcharran, H. (2002). An Empirical Analysis Of The Determinants Of The P/E Ratio İn Emerging Markets. Emerging Markets Review, 3(2), 165-178.

Sezgin, F. H. (2010). An Empirical Investigation Of The Relationship Among P/E Ratio, Stock Return And Dividend Yiels For Istanbul Stock Exchange. International Journal Of Economics And Finance Studies, 1(2), 16-23. 
FSECON YÜKSEL, S., CANÖZ, I., ADALI, Z., (2017), “Türkiye'deki Mevduat Bankalarının Fiyat-Kazanç Oranını Etkileyen Değişkenlerin Mars Yöntemi İle Belirlenmesi”, Fiscaoeconomia, Vol.1(3), 40-55.

Shamsuddin, A. F., \& Hillier, J. R. (2004). Fundamental Determinants Of The Australian PriceEarnings Multiple. Pacific-Basin Finance Journal, 12(5), 565-576.

White, C. B. (2000). What P/E Will The US Stock Market Support?. Financial Analysts Journal, 30-38.

Zarowin, P. (1990). What Determines Earnings-Price Ratios: Revisited. Journal of Accounting, Auditing \& Finance, 5(3). 